\title{
The Influence of Intravenous Lipopolysaccharide Injection on TLR4 Transcription Levels in Duck (Anas domestica) Liver, Spleen and Bursa of Fabricius
}

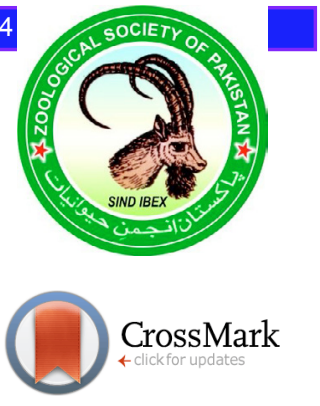

\author{
Jun-Ying Liu, He-He Liu*, Jie Kou, Yang-Mei Zhao, Ji-Wen Wang, Liang Li \\ and Xiao-Hui Du \\ Farm Animal Genetic Resources Exploration and Innovation Key Laboratory of \\ Sichuan Province, College of Animal Science and Technology, Sichuan Agricultural \\ University, Chengdu, Sichuan 611130, P.R. China
}

\begin{abstract}
A B S T R A C T
TLR4 is a member of the toll-like receptor family and can recognize lipopolysaccharide (LPS), the main component of gram-negative bacteria. To investigate how TLR4 responds to LPS, the TLR4 transcription levels in duck liver, spleen and bursa of Fabricius were examined after a model for immune stress was implemented through LPS injection in Peking ducks. The results from this assay suggested that LPS injection significantly increased the concentration of tumor necrosis factor- $\alpha$ (TNF- $\alpha$ ) in bursa of Fabricius $(P<0.05)$, along with an increase in the concentrations of immunoglobulin-G (IgG) and interleukin-12 (IL-12) in the serum of ducks at 1 day and 7 days after LPS injection $(P<0.05)$. However, there were no apparent changes in organ index or the relative expression of TLR4 and IgM $(P>0.05)$. Furthermore, correlation analysis showed a positive relationship between the mRNA expression of TLR4 and concentrations of TNF- $\alpha$ and IL-12. These results revealed that although there were no significant effects of LPS injection on TLR4 mRNA expression in lymphoid organs, the response to LPS may not mainly rely on the transcription of $T L R 4$, and the downstream molecular response in the immune system may contribute more to the TLR4 signaling cascade.
\end{abstract}

\begin{tabular}{l} 
Article Information \\
\hline Received 24 July 2015 \\
Revised 11 August 2017 \\
Accepted 12 December 2017 \\
Available online 11 May 2018 \\
Authors' Contribution \\
JYL, YMZ and JK conducted all \\
experiments. JYL, HHL, JWW, LL \\
and XHD designed the experiments \\
and drafted manuscript. \\
Key words \\
LPS, Toll-like receptor 4, Immunity \\
index, Peking duck, Tumor \\
necrosis factor $-\alpha$, Interleukin-12, \\
Immunoglobulin-G
\end{tabular}

\section{INTRODUCTION}

$\mathrm{T}$ he innate immune system is the first response in protecting the body from foreign intruders. The initiation of innate immune responses is characterized by a recognition of microbial pathogens, such as the inflammatory response, which is mediated by pattern recognition receptors (PRRs) (Kawai and Akira, 2011). The PRRs mainly include two types of receptors: tolllike receptors (TLRs), which are membrane-bound receptors and can recognize extracellular pathogens; and intracellular PRRs, which include the nucleotide binding oligomerization domain (NOD)-like receptors (NLRs) and the retinoic acid inducible gene-I (RIG-I)-like receptors (RLRs). As important members of PRRs, TLRs mainly act as sensors for conserved microbial components, where these receptors play a critical role in activating and initiating innate immunity. It has been clarified that different TLRs recognize differential pathogen-associated molecular patterns (PAMP). TLR2 mainly mediates the

\footnotetext{
* Corresponding author: liuee 1985@sicau.edu.cn 0030-9923/2018/0004-1237 \$ 9.00/0

Copyright 2018 Zoological Society of Pakistan
}

response to cell-wall components of gram-positive bacteria (Takeuchi et al., 1999). TLR3 has been proven to recognize double-strand RNA and synthetic RNA. TLR9 can recognize the CpG motif of bacterial DNA (Armant and Fenton, 2002; Boyd et al., 2007). Lastly, TLR4 mainly recognizes lipopolysaccharide (LPS), which is released from the cell walls of dead gram-negative bacteria and, therefore, plays essential roles in initiating inflammatory responses.

When host species are infected by gram-negative bacteria, TLR4 embedded in the membrane of host cells will recognize LPS and release pro-inflammatory cytokines, such as tumor necrosis factor (TNF)- $\alpha$, interleukin (IL)6, and IL-12, to initiate the inflammatory response (Nomura et al., 2000). LPS has been shown to cause multiple sickness symptoms in both avian and mammals, including changing body temperature, reducing growth performance and immune functions (Star et al., 2008; Jiang et al., 2011b). Musa et al. (2009) demonstrated the exposure of chicken peripheral blood mononuclear cells to avian pathogenic $E$. coli resulted in rapid changes in both inflammatory and anti-inflammatory cytokines, which are both important in regulating the immune response (Musa et al., 2009). In ducks, Zhu (2009) investigated the 
harmful effect of bacterial endotoxin on ducks' organs by observing the pathological sections of organs following LPS injection (Zhu et al., 2009). Therefore, LPS was often used as a model antigen to study an animals' susceptibility to pathogens by mimicking bacterial infection (Gray et al., 2012; Nord et al., 2013).

As the specificity recognition receptor of LPS, TLR4 has been implicated in signal transduction by its extracellular leucine-rich repeat (LRR) domain, which associates with the LPS-LPS binding protein (LBP)-CD14 compounds. Additionally, when TLR4 binds to its ligand, the Toll/interleukin-1 receptor (TIR) homology domain (a cytoplasmic conserved region of TLR4) begins to interact with its downstream protein kinases (Armant and Fenton, 2002; Underhill, 2002). Subsequently, nuclear factor (NF)$\kappa \mathrm{B}$ signaling is activated and the inflammatory cascade reactions are initiated (Chow et al., 1999; Visintin, 2005). Previous studies concentrated more on the mechanism of TLR4 responding to LPS with regards to the proteinprotein interactions, whereas the effect of LPS on mRNA expression levels of TLR4 was seldom documented. The effect of LPS challenge on TLR 4 mRNA expression has been documented in a broad range of cell populations. In humans, Song et al. (2001) confirmed that TLR4 mRNA was expressed in corneal epithelial cells and expression levels increased with the presence of LPS (Song et al., 2001). It also has been confirmed that the mRNA expression of TLR4 could be induced by LPS in the peritoneal macrophages of zebra finches and duck embryo fibroblasts (Vinkler et al., 2009; Zhao et al., 2013).

In avian, the spleen and bursa of Fabricius are the major lymphoid organs, both playing key roles in immune function. It has been proven that TLR 4 is expressed in the ceacal tonsil and the spleen in chickens (Iqbal et al., 2005). However, it was not clear whether the expression of TLR4 could be influenced by LPS in these lymphoid. Therefore, the present study attempted to study the effects of LPS on the expression of TLR4 in duck lymphoid organs (the spleen and bursa of Fabricius), as well as the levels of IgM and cytokines during the inflammatory process, all of which are typical immune molecular markers. These studies may expand our understanding to the mechanism of TLR4 response to LPS.

\section{MATERIALS AND METHODS}

\section{Animals}

Twelve Peking ducks from the Waterfowl Breeding Farm at Sichuan Agricultural University were used in this study, and each duck weighed, on average, $2.041 \pm 0.1801$ $\mathrm{kg}$. Food and water were available ad libitum. At 36 days of age, the ducks were randomly divided into two groups of six (control in=6; LPS $n=6$ ). The LPS group was injected with an LPS-PBS solution (LPS powder was dissolved with $1 \mathrm{~mL}$ sterile PBS) in vein at a dose concentration of $400 \mu \mathrm{g} / \mathrm{kg}$ BW (body weight) (Jiang et al., 2011b). The control group was injected the same dose of sterile PBS. After $24 \mathrm{~h}$, the above-mentioned process was repeated.

\section{Blood collection and sampling}

After fasting for $12 \mathrm{~h}$, blood was sampled using a $5 \mathrm{ml}$ syringe through a vein in the duck's right shank at 1 day after the final LPS injection (1 dpi) and 7 dpi. Blood samples were maintained for 30 minutes at room temperature and then centrifuged for 10 minutes at $3000 \mathrm{~g}$. The serum was collected and stored at $-20^{\circ} \mathrm{C}$ immediately. At $7 \mathrm{dpi}$, the twelve ducks from the two groups were weighed. Next, the ducks were sacrificed, and the liver, spleen and bursa of Fabricius were separated from adhering tissues and accurately weighed. The organ index was calculated by the relative weight (grams) of the spleen, bursa of Fabricius and liver to BW (kilogram). The organ samples were frozen in liquid $\mathrm{N}_{2}$ and stored at $-80^{\circ} \mathrm{C}$ until use. All procedures were approved by the Beijing Animal Welfare Committee.

\section{ELISA assay for cytokines}

The samples (liver, spleen and bursa of Fabricius) were made into $10 \%$ tissue homogenate through homogenizing in ice-cold phosphate buffer saline (PBS) according to a $\mathrm{W} / \mathrm{V}$ at $1: 10$ and then centrifuged at $3000 \mathrm{rpm}$ for $10 \mathrm{~min}$ at $4^{\circ} \mathrm{C}$. The collected supernatants were stored at $-20^{\circ} \mathrm{C}$. The amounts of TNF- $\alpha$, IL-12 in both serum and organ samples were measured using ELISA kits (Qisong, Beijing, China) according to the manufacturer's protocols.

\section{$R N A$ extraction and real-time PCR}

Total RNA from all samples was extracted using Trizol (Invitrogen, USA), following the manufacturer's instructions. RNAs were reverse transcribed using PrimeScript ${ }^{\circledR}$ RT reagent Kit (TaKaRa, Japan) according to the manufacturer's instructions. Real-time PCR primers for each of the genes of interest were designed, and the primer sequences are listed in Table I. GAPDH (AY436595) and $\beta$-actin (EF667345) were used as the housekeeping genes. The SYBR ${ }^{\circledR}$ ExScript ${ }^{\mathrm{TM}}$ RT-PCR Kit (TaKaRa, Japan) was used for real-time PCR, which was carried out using an iCycler IQ5 Multicolor Real-Time PCR Detection System (Bio-Rad, CA, USA). The real-time PCR procedures included $3 \mathrm{~min}$ of pre-denaturation at $95^{\circ} \mathrm{C}$, followed by 40 cycles of denaturation at $95^{\circ} \mathrm{C}$ for $30 \mathrm{~s}$ and $60^{\circ} \mathrm{C}$ for $40 \mathrm{~s}$. Real-time PCR analysis of each sample was repeated in triplicate. The data were calculated by the normalized relative quantification method followed by $2^{-\Delta \Delta \mathrm{Ct}}$ (Livak and Schmittgen, 2001). 
Table I.- The primer sequences for real-time PCR.

\begin{tabular}{llll}
\hline Gene name & Primers sequences & Product size(bp) & GenBank ID \\
\hline TLR4 & F:GCTTGCTGCATTGGTGTTCATA & 131 & JN618073 \\
& R:AGTGGATAACAAAGGCATCATAGGT & & APU27213 \\
IgM & F:ACCTCTTCATCCGTTGGCTCC & 103 & AY436595 \\
& R:GTGAAGTAAGAGCGCGCCAGT & & EF667345 \\
GAPDH $^{*}$ & F:AAGGCTGAGAATGGGAAAC & 254 & \\
& R:TTCAGGGACTTGTCATATTC & & 92 \\
\hline
\end{tabular}

The genes marked with“*” are housekeeping genes.

\section{Data analysis}

The results are expressed as the mean \pm SEM and analyzed statistically using GLM procedures for a one-way analysis of variance. The Spearman's correlation analysis was used to determine whether the expressions of TLR4 mRNA in tissues correlated with organ index, cytokines production and parameters in serum. All of the statistical analyses were performed using SAS V.8.0 (SAS Institute Inc., Cary, NC, USA). A value for $\mathrm{P}<0.05$ was considered significant.

\section{RESULTS}

\section{Organ index}

The results of the organ index were not significantly affected after ducks were injected with LPS (Table II). The liver index and bursa of Fabricius index decreased by $11.37 \%$ and $12.41 \%$, respectively, compared with the control group $(\mathrm{P}>0.05)$. However, the spleen index increased by $13.92 \%$ after LPS injection compared with the control group $(P>0.05)$.

Table П.- Organ indices.

\begin{tabular}{llll}
\hline & $\begin{array}{l}\text { Liver } \\
(\mathbf{g} / \mathbf{k g})\end{array}$ & $\begin{array}{l}\text { Spleen } \\
(\mathbf{g} / \mathbf{k g})\end{array}$ & $\begin{array}{l}\text { Bursa of Fabricius } \\
(\mathbf{g} / \mathbf{k g})\end{array}$ \\
\hline Control & $26.65 \pm 0.87$ & $0.79 \pm 0.06$ & $1.45 \pm 0.09$ \\
Treatment & $23.62 \pm 2.28$ & $0.90 \pm 0.08$ & $1.27 \pm 0.18$ \\
\hline
\end{tabular}

The label "*” on the each item indicates a significant difference between the different groups $(\mathrm{P}<0.05), \mathrm{n}=6$.

Concentrations of TNF- $\alpha, I L-12$, and $\operatorname{Ig} G$ and $T-S O D$ activity

As shown in Figures $1 \mathrm{~A}$ and $\mathrm{B}$, the LPS-treated ducks secreted a larger amount of TNF- $\alpha$ in the bursa of
Fabricius at 7 dpi $(P<0.05)$. However, IL-12 levels in the liver and spleen were reduced significantly after the ducks were injected by LPS for 7 days $(P<0.05$, Fig. 1C). LPS injection had a significant influence on the concentrations of IgG and IL-12 in the serum from the ducks at 1 dpi and 7 dpi, respectively $(P<0.05$, Fig. $1 \mathrm{D}, \mathrm{E})$. In addition, there were no significant effects on T-SOD activity when the ducks were injected with LPS at $1 \mathrm{dpi}$ and $7 \mathrm{dpi}(\mathrm{P}>0.05)$.

\section{TLR4 and IgM mRNA expression levels}

It has been shown that the stimulation of bacterial LPS slightly down-regulated the relative expression of TLR4 mRNA (Fig. 2A, $P>0.05$ ). The expression of IgM had a trend in variation that was similar to TLR4 in spleen, bursa of Fabricius and liver, with the mRNA levels of both reduced after LPS injection compared with the control group (Fig. 2B, $P>0.05$ ).

\section{Relative expression of TLR4 $m R N A$ and immunity indices}

In the liver, the mRNA expression of TLR4 had a positive relationship with the production of TNF- $\alpha$ and the organ index respectively following injection of LPS $(P<0.01)$. In the spleen, there was a strong positive relationship between the mRNA expression of TLR4 and the concentration of TNF- $\alpha$ in the treatment group $(P<0.01)$ (Table III). The correlation between these two values in the treatment group was greater than in the control group. Additionally, in the bursa of Fabricius, the correlation between the TLR4 mRNA expression and IL-12 production also increased after LPS injection. In addition, there was a significant positive correlation between TLR4 mRNA expression and the organ index in the bursa of Fabricius under LPS challenge $(P<0.01)$ compared with the negative correlation of these values before LPS injection. However, in lymphoid organs, bacterial LPS had no significant effect on the relationship between TLR4 mRNA expression and T-SOD activity or IgG concentration in the serum overall. 
Tissue TNF- $\alpha$

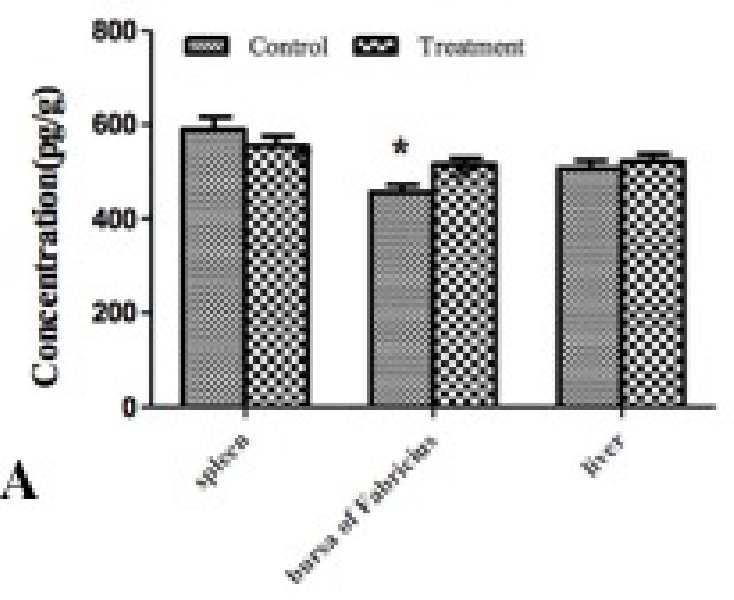

Tissue IL-12

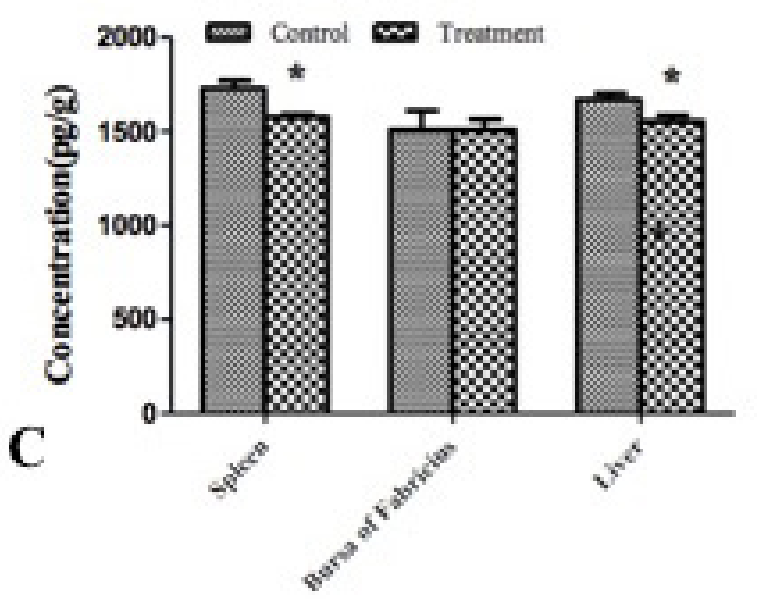

Serum IgG

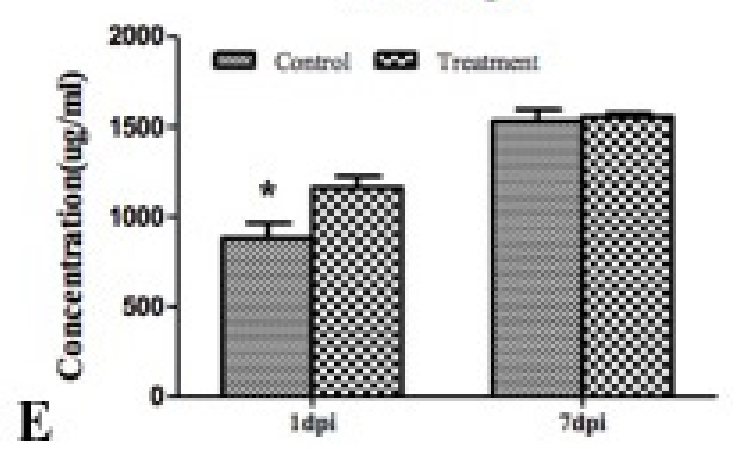

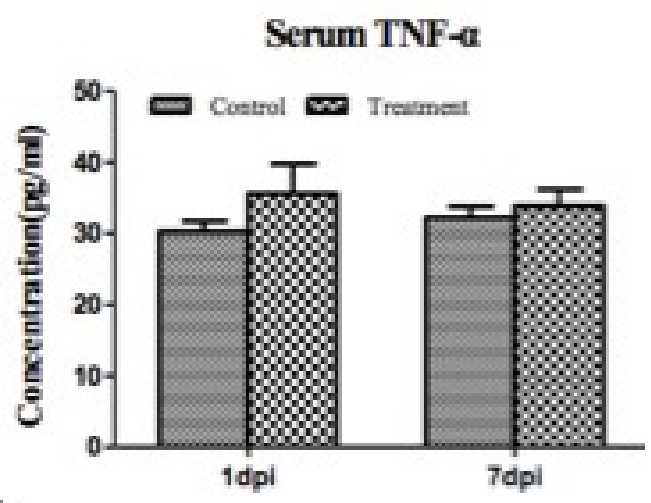

B
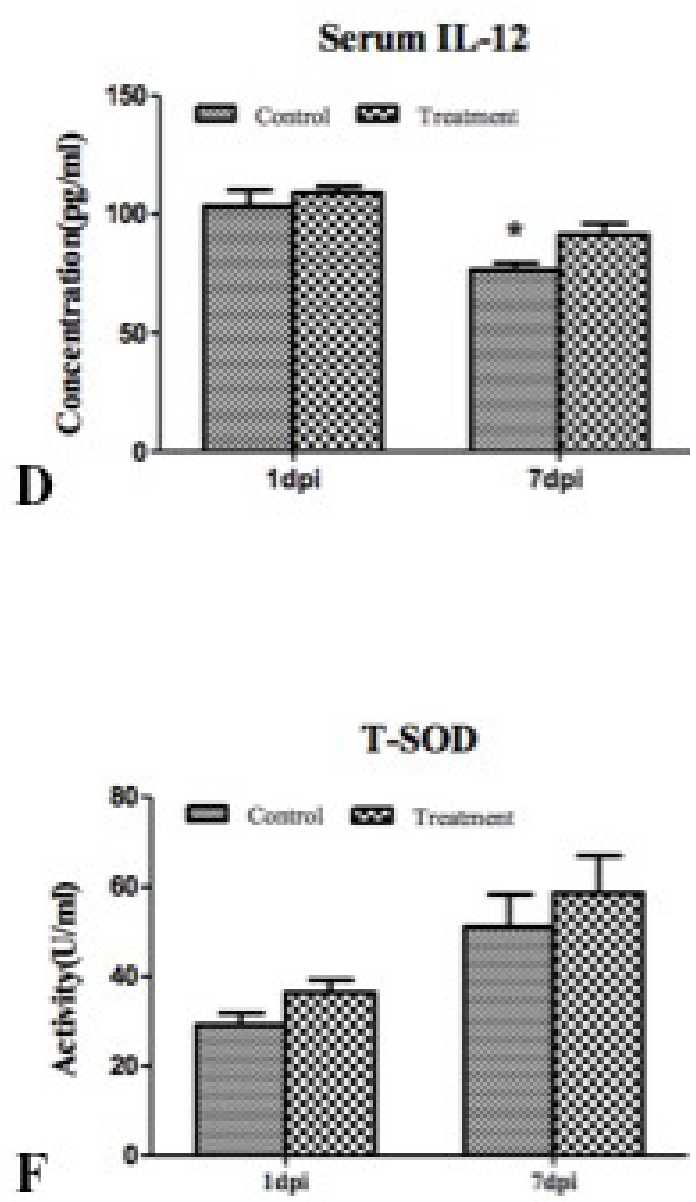

Fig. 1. Changes in TNF- $\alpha$, IL-12, and IgG concentrations and T-SOD activity. A, the tissue concentrations of TNF- $\alpha$ in control and treatment groups; B, the serum TNF- $\alpha$ levels in control and treatment groups; C, the tissue concentrations of IL-12 in control and treatment; D, the serum IL-12 concentration in control and treatment; E, the serum concentrations of IgG in control and treatment groups; F, the T-SOD activity of serums in control and treatment groups. The label "*” on each item indicates a significant difference between the different groups $(\mathrm{P}<0.05), \mathrm{n}=6$. "dpi" represents the days post injection of LPS. 

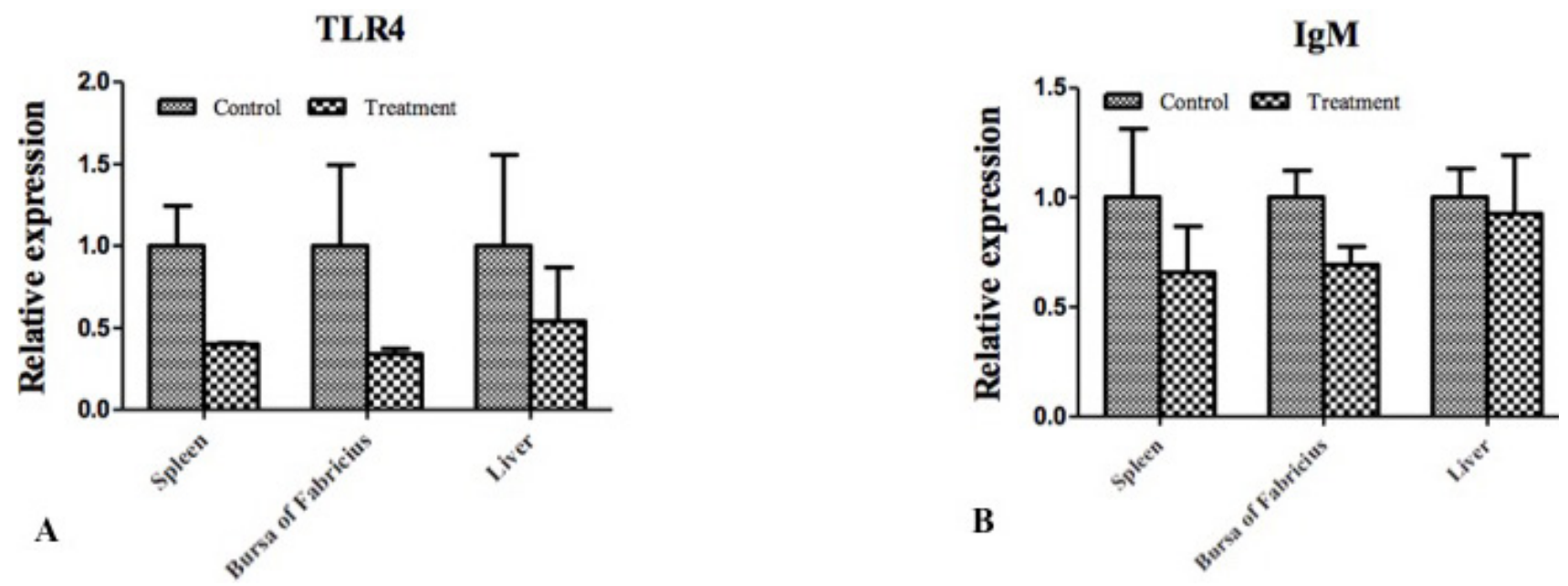

Fig. 2. Changes in TLR4 and IgM mRNA expression in tissues. Panel A \& B show the relative expression of TLR4 and IgM, respectively, in liver, spleen and bursa of Fabricius between control and treatment groups. The label "** on each item indicates a significant difference between the different groups $(\mathrm{P}<0.05), \mathrm{n}=4$

Table III.- Association of the TLR4 gene expression and immunity indexes

\begin{tabular}{|c|c|c|c|c|c|c|}
\hline & \multicolumn{2}{|c|}{ Liver TLR4(mRNA) } & \multicolumn{2}{|c|}{ Spleen TLR4(mRNA) } & \multicolumn{2}{|c|}{ Bursa of Fabricius TLR4(mRNA) } \\
\hline & Control & Treatment & Control & Treatment & Control & Treatment \\
\hline TNF- $\alpha$ & 0.3 & $1.0^{* *}$ & 0.5 & $1.0 * *$ & 0.5 & -0.5 \\
\hline IL-12 & 0.1 & -0.5 & 0.5 & -0.5 & 0.5 & $1.0 * *$ \\
\hline Organ index & -0.8 & $1.0^{* *}$ & -0.5 & 0.5 & -0.5 & $1.0^{* *}$ \\
\hline IgG Serum(1dpi) & -0.3 & -0.5 & -0.5 & 0.5 & $-1.0^{* *}$ & -0.5 \\
\hline T-SOD Serum(1dpi) & -0.6 & -0.5 & $-1.0 * *$ & 0.5 & -0.5 & -0.5 \\
\hline
\end{tabular}

The label "***" on the each data indicates a highly significant difference between the different groups $(\mathrm{P}<0.01), \mathrm{n}=4$. "dpi" indicates days post injection.

\section{DISCUSSION}

Colibacillosis, which is primarily caused by the gramnegative bacteria Escherichia coli, is one of the major bacterial diseases in ducks. The growth of E. coli could lead to LPS contamination in water and in animals' blood (Jiang et al., 2011a; Liu and Wang, 2012; Shi zhendan, 2011). In the present study, ducks were injected with LPS, and the subsequent phenotypic and molecular changes were measured and compared between control and treatment ducks. Our results showed that the organ index was not significantly changed following LPS injection, but there was a numerical reduction in the organ index, which was similar to the results of Chen's studies in piglets where the spleen and thymus index were significantly reduced in the LPS injection group after 14 days (Chen et al., 2010). These phenomena suggest that LPS might have a repression effect on the development of lymphoid organs. This discrepancy in whether the changes of immune indexes were significant after LPS injection is most likely due to the difference in the anti-infection response between pigs and ducks. In addition, the mRNA expression of IgM, an efficient anti-microbial molecule, was not significantly changed in the LPS group compared with the control. This result was contrary to Dresser's research demonstrating that LPS-induced B lymphocytes make IgM antibodies increase after intravenous injection of LPS in mice (Dresser, 1978). On the whole, the influences of LPS on lymphoid organs and duck immunity were not obvious, and these effects may be connected to the concentration of the dose of LPS and be time-dependent.

As the specific receptor for LPS in pathogen recognition, the importance of TLR4 in initiating a rapid innate immune response was proven by the fact that TLR4-deficient mice are LPS hyporesponsive but respond normally to gram-positive bacteria (Takeuchi et al., 1999). The objective of our study was to test whether the transcription levels of TLR4 will be influenced when faced 
with an inflammatory stimulus in duck. We found that LPS down-regulated the mRNA expression of TLR4 slightly. Tu et al. (2007) detected that in chickens, TLR4 mRNA levels reduced $24 \mathrm{~h}$ after LPS treatment, and these results were similar to ours. However, Wu et al. (2008) reported that the mRNA expression of TLR4 increased after the injection of LPS in rats. The reduction of TLR4 mRNA levels suggested that the anti-inflammatory response occurred to prevent the amplification of the inflammatory response and to alleviate the injury of infection. Thus, this down-regulation of TLR4 protected the body from an excessive inflammatory response to some extent (Swank and Deitch, 1996; Tu et al., 2007; Wu et al., 2008). Based on our data, there were no significant differences in TLR4 mRNA expression between the control and treatment groups. Changes in mRNA expression may depend on the concentration of the dose of LPS as well as the time, which may decide the effects of the inflammatory responses (Chow et al., 1999). Furthermore, the suppression of TLR4 mRNA levels was thought to be involved in the LPStolerance caused by the repeated injection of LPS (Nomura et al., 2000). Overall, we proposed that the influences of LPS on TLR4 may not primarily rely on mRNA levels, but might be achieved through mediating the cascade of TLR4 downstream signaling.

The expression of TLR4 is relatively close to the secretion of inflammatory cytokines (Li et al., 2011). Cytokine production is a functional effect of LPS, and plays an important role in regulating inflammatory responses (Kogut et al., 2005). TNF- $\alpha$ and IL-12 induced by LPS are the main pro-inflammatory cytokines involved in inflammatory responses (Ozmen et al., 1994). In Blanque's et al. (1996) report, the sampling points were selected between 1 and $8 \mathrm{~h}$ after injection of LPS in mice. This group found that the peak levels of TNF- $\alpha$ expression were detected at $1-2 \mathrm{~h}$ and that these levels declined rapidly to control levels (Blanque et al., 1996). Kobayashi et al. (2013) found that compared with wild type mice, LPSinduced TNF- $\alpha$ and IL-12 production in dendritic cells and macrophages was significantly enhanced in BTLA 1- (B and T lymphocyte attenuator) mice after treatment for one and four hours, respectively (Kobayashi et al., 2013). As the typical indicator of acquired immunity, the production of serum IgG suggested the capacity of animals to overcome the invasion of pathogen. Additionally, SOD can combine with nitric oxide, which is released by activation macrophages and the hepatic cell, to resist liver injury (Josephs et al., 2000). From our results, LPS injection increased the concentration of TNF- $\alpha$ both in bursa of Fabricius, as well as the concentrations of IL12 in serum. There was also a significant increase in IgG production between the control and treatment groups at 1 dpi. Thus, these results suggest that animals would initiate the defense mechanism by releasing a large amount of cytokines to resist challenges from bacteria.

Furthermore, correlation analysis between TLR4 expression and immunity indexes showed that there were strong positive relationships between TLR4 mRNA expression and the concentrations of TNF- $\alpha$ and IL-12 after LPS injection. These data suggest that the effects of the inflammatory response induced by LPS had led to a broad range of cytokine production. At the same time, a significant positive correlation was found between TLR4 mRNA expression and organ index in the treatment group, which was contrary to the correlation before the LPS challenge. In the present experiment, we found that bacterial infections would influence the production of TNF- $\alpha$ and IL-12 in liver, lymphoid organs and serum. This was especially noticeable when considering the concentration of TNF- $\alpha$, as it increased when ducks encountered the invading LPS. Additionally, LPS injection was also found to increase IgG concentration in serum at 1dpi. Along with this, there were significant correlations between the mRNA expression of TLR4 and the concentration of TNF- $\alpha$ and IL-12 after LPS injection. Thus, even though LPS had no significant influence on the expression of TLR4 mRNA in lymphoid organs, the effects of LPS during the inflammatory response were not always dependent on the transcription of TLR4 mRNA. However, LPS may be involved in the cascade amplification of TLR4, which activates the signaling of LPS/TLR4 and influences a large range of other downstream genes and the release of cytokines.

\section{Statement of conflict of interest}

The authors declare no conflict of interest.

\section{ACKNOWLEDGMENTS}

This work was supported by the Major Project of the Sichuan Education Department (13ZA0252), the Chinese Agriculture Research Service (No.CARS43-6), the National Natural Science Foundation of China (No.31301964), and by the Breeding of Multiple Crossbreeding Systems in Waterfowl (2011NZ0099-8).

\section{REFERENCES}

Armant, M.A., and Fenton, M.J., 2002. Toll-like receptors: a family of pattern-recognition receptors in mammals. Genome Biol., 3: 3011-3016. https:// doi.org/10.1186/gb-2002-3-8-reviews3011

Blanque, R., Meakin, C., Millet, S. and Gardner, C.R., 1996. Hypothermia as an indicator of the 
acute effects of lipopolysaccharides comparison with serum levels of IL1 $\beta$, IL6 and TNF $\alpha$. Gen. Pharmacol., 27: 973-977. https://doi. org/10.1016/0306-3623(95)02141-8

Boyd, A., Philbin, V.J. and Smith, A.L., 2007. Conserved and distinct aspects of the avian toll-like receptor (TLR) system: implications for transmission and control of bird-borne zoonoses. Biochem. Soc., 35: 1504-1507. https://doi.org/10.1042/BST0351504

Chen, J., Liu, X., Zhang, F. and Bian, L., 2010. Effects of dietary glutamine on immune organ in inflammatory-stressed piglets. Chinese J. Vet. Med., 46: 3-5.

Chow, J.C., Young, D.Y., Golenbock, D.T., Christ, W.J. and Gusovsky, F., 1999. Toll-like receptor-4 mediates lipopolysaccharide-induced signal transduction. J. biol. Chem., 274: 10689-10692. https://doi.org/10.1074/jbc.274.16.10689

Dresser, D.W. 1978. Most IgM-producing cells in the mouse secrete auto-antibodies (rheumatoid factor). Nature, 274: 480-483. https://doi. org/10.1038/274480a0

Gray, D.A., Marais, M. and Maloney, S.K., 2012. A review of the physiology of fever in birds. J. Comp. Physiol. B., 183: 297-312. https://doi.org/10.1007/ s00360-012-0718-z

Iqbal, M., Philbin, V.J. and Smith, A.L., 2005. Expression patterns of chicken Toll-like receptor mRNA in tissues, immune cell subsets and cell lines. Vet. Immunol. Immunop., 104: 117-127. https://doi.org/10.1016/j.vetimm.2004.11.003

Jiang, D., Liu, L., Wang, C., Chen, F., Sun, A. and Shi, Z., 2011a. Raising on water stocking density reduces geese reproductive performances via aater bacteria and lipopolysaccharide contaminations in "Geese-Fish" production system. Agric. Sci. China, 10: 1459-1466. https://doi.org/10.1016/S16712927(11)60139-9

Jiang, D., Liu, L., Chen, F., Wang, C., Sun, A. and Shi, Z., 2011b. Effects of LPS on growth performance and immune function in meat geese. China Poult., 33: $10-15$.

Josephs, M., Bahjat, F. and Fukuzuka, K., 2000. Lipopolysaccharide and D-galactosamine-induced hepatic injury is mediated by TNF- $\alpha$ and not by Fas ligand. Am. J. Physiol., 278: R1196-R1201.

Kawai, T. and Akira, S., 2011. Toll-like receptors and their crosstalk with other innate receptors in infection and immunity. Immunity, 34: 637-650. https://doi.org/10.1016/j.immuni.2011.05.006

Kobayashi, Y., Iwata, A., Suzuki, K., Suto, A., Kawashima, S., Saito, Y., Owada, T., Kobayashi,
M., Watanabe, N. and Nakajima, H., 2013. B and $\mathrm{T}$ lymphocyte attenuator inhibits LPS-induced endotoxic shock by suppressing Toll-like receptor 4 signaling in innate immune cells. Proc. natl. Acad. Sci., 110: 5121-5126. https://doi.org/10.1073/ pnas. 1222093110

Kogut, M., Iqbal, M., He, H., Philbin, V., Kaiser, P. and Smith, A., 2005. Expression and function of Tolllike receptors in chicken heterophils. Devel. Comp. Immunol., 29: 791-807. https://doi.org/10.1016/j. dci.2005.02.002

Li, J., Wang, S., Zhang, H., Qin, J., Li, S., Yu, H., Wang, F., Li, Y. and Liu, S., 2011. Expression and role of Toll like receptor in multiple organ injury inducedby bacterial pneumonia in aged rats. Chinese $J$. Gerontol., 12: 4585-4588.

Liu, X. and Wang, Y., 2012. Current situation, problems and proposals for waterfowl industrial development in china. Res. Argric. Modern., 33: 140-144.

Livak, K.J. and Schmittgen, T.D., 2001. Analysis of relative gene expression data using realtime quantitative PCR and the $2^{-\Delta \Delta \mathrm{CT}}$ method. Methods, 25: 402-408. https://doi.org/10.1006/ meth.2001.1262

Musa, H.H., Wu, S., Zhu, C., Zhu, J. and Zhu, G., 2009. Immune response of peripheral blood mononuclear cells to avian pathogenic Escherichia coli. Annl. Microbiol., 59: 587-592. https://doi.org/10.1007/ BF03175150

Nomura, F., Akashi, S., Sakao, Y., Sato, S., Kawai, T., Matsumoto, M., Nakanishi, K., Kimoto, M., Miyake, K., Takeda, K. and Akira, S., 2000. Cutting edge:endotoxin tolerance in mouse peritoneal macrophages correlates with down-regulation of surface toll-like receptor 4 expression. J. Immunol., 164: 3476-3479. https://doi.org/10.4049/ jimmunol.164.7.3476

Nord, A., Chiriac, S., Hasselquist, D., Nilsson, J-Å. and Martin, L.B., 2013. Endotoxin injection attenuates rest-phase hypothermia in wintering great tits through the onset of fever. Funct. Ecol., 27: 236244. https://doi.org/10.1111/1365-2435.12003

Ozmen, L., Pericin, M., Hakimi, J., Chizzonite, R.A., Wysocka, M., Trinchieri, G., Gately, M. and Garotta, G., 1994. Interleukin 12, interferon gamma, and tumor necrosis factor alpha are the key cytokines of the generalized Shwartzman reaction. J. exp. Med., 180: 907-915. https://doi.org/10.1084/ jem.180.3.907

Shi, Z., Liu, L. and Sun, A., 2011. Study on the harm of "waterfowl-fish" production system to the production performance of waterfowl. China 
Poult., 33: 1-3.

Song, P.I., Abraham, T.A., Park, Y., Zivony, A.S., Harten, B., Edelhauser, H.F., Ward, S.L., Armstrong, C.A. and Ansel, J.C., 2001. The expression of functional LPS receptor proteins CD14 and toll-like receptor 4 in human corneal cells. Invest. Ophthalmol. Vis. Sci, 42: 2867-2877.

Star, L., Kemp, B., Anker, I. van den. and Parmentier, H.K., 2008. Effect of single or combined climatic and hygienic stress in four layer lines: 1. Performance. Poult. Sci., 87: 10221030. https://doi.org/10.3382/ps.2007-00142 https://doi.org/10.3382/ps.2007-00143

Swank, G.M. and Deitch, E.A., 1996. Role of the gut in multiple organ failure: Bacterial translocation and permeability changes. World J. Surg., 20: 411-417. https://doi.org/10.1007/s002689900065

Takeuchi, O., Hoshino, K., and Kawai, T., 1999. Differential roles of TLR2 and TLR4 in recognition of gram-negative and gram-positive bacterial cell wall components. Cell Press, 11: 443-451. https:// doi.org/10.1016/S1074-7613(00)80119-3

Tu, J., Wang, Y., Peng, K., and Qi, K., 2007. Effect on TLR4 mRNA expression and injury of multitude organs after challenged with lipopolysaccharide in chickens. J. Biol., 24: 13-15.

Underhill, D.M. and Ozinsky, A., 2002. Toll-like receptors: Key mediators of microbe detection.
Immunology, 14: 103-110. https://doi.org/10.1016/ S0952-7915(01)00304-1

Vinkler, M., Bryjová, A., Albrecht, T. and Bryja, J., 2009. Identification of the first toll-like receptor gene in passerine birds: TLR4 orthologue in zebra finch (Taeniopygia guttata). Tissue Antigens, 74: 32-41. https://doi.org/10.1111/j.1399-0039.2009.01273.x

Visintin, A., Halmen, K.A., Latz, E., Monks, B.G. and Golenbock, D.T., 2005. Pharmacological inhibition of endotoxin responses is achieved by targeting the TLR4 coreceptor, MD-2. J. Immunol., 175: 6465-6472. https://doi.org/10.4049/ jimmunol.175.10.6465

Wu, Y., Zhang, J., Bai, M., Zhang, L., Bao, B. and Liang, H., 2008. Influence of inhaling nitric oxide on the expression of TLR4 in rats with lipopolysaccharideinduced acute lung Injury. Acta Med. Univ. Sci. Technol. Huazhong, 37: 583-586.

Zhao, W., Huang, Z., Chen, Y., Zhang, Y., Rong, G., $\mathrm{Mu}, \mathrm{C}$, $\mathrm{Xu}, \mathrm{Q}$. and Chen, G., 2013. Molecular cloning and functional analysis of the duck TLR4 gene. Int. J. mol. Sci., 14: 18615-18628. https://doi. org/10.3390/ijms140918615

Zhu, Z., Liu, J., Liang, S., Yang, M., Chen, Y. and Gu, C., 2009. Pathological research on the injury of E.coli endotoxin to duck's viscera. Chinese J. Trad. Vet. Sci., $72-78$. 